\title{
ТЕОРЕТИЧЕСКАЯ МОДЕЛЬ СОЦИОЛОГИЧЕСКОГО АНАЛИЗА ЦЕННОСТИ ЗДОРОВЬЯ НАСЕЛЕНИЯ АРКТИЧЕСКОГО РЕГИОНА РОССИЙСКОЙ ФЕДЕРАЦИИ
}

\author{
Буланова Юлия Витальевна, \\ ybus@mail.ru
}

Северный государственный медицинский университет,
Россия, 163000, г. Архангельск, пр. Троицкий, 51

Буланова Юлия Витальевна, младший научный сотрудник Центральной научноисследовательской лаборатории Северного государственного медицинского университета.

Представлена теоретическая модель социологического анализа ценности здоровья как многокомпонентная система. Приведено описание компонентов модели и их характеристик. Исследованы факторы информированности, поведенческой активности, здоровьесбережения, персональной ответственности за здоровье. Подчеркнута особенная актуальность в условиях Арктической зоны с присущими особенностями климатогеографического положения и экстремальностью жизнеобеспечения. Актуальность вопросы изучения ценности здоровья населения обрели в условиях глобализации ХХІ в. Назрела необходимость решения проблем сохранения здоровья человека. Особенную остроту приобретает эта проблема в условиях Арктической зоны Российской Федерации. Природные и антропогенные факторы предъявляют повышенные требования к функциональным системам организма человека, осложняют труд, быт и отдых населения, являясь факторами риска нарушений здоровья. Особую актуальность проблемы здоровья обрели во время пандемии нового коронавируса COVID-19. Это один из худших мировых кризисов в сфере здравоохранения за последние 50 лет. На первый план встали вопросы обеспечения санитарно-эпидемиологического благополучия, здоровьесбережения, повышения ценности здоровья. Цель работы - рассмотрение ценности здоровья населения Арктического региона Российской Федераџии через призму теоретических основ и институциональных подходов. Методы: аксиологический подход, предполагающий ценностное измерение исследуемых социокультурных явлений, и социально-конструктивистский подход, рассматривающий ценность здоровья населения Арктического региона как необходимую социальную парадигму. Выводы: во-первых, создание теоретической модели, ее использование в социологическом анализе ценности здоровья населения Арктического региона Российской Федерации и представление исследуемого объекта с разных сторон позволяют достичь наибольшей содержательности и полноты понятий, относящихя к данной области знаний. Во-вторых, содержание теоретической модели, предлагаемой нами, представляет собой определенную целостность, которая в неразрывном единстве включает изучение конкретных аспектов жизни общества, взаимосвязей, а также возможности и способы ее использования в исследовательской деятельности. Благодаря моделированию, при сопоставлении характеристик с конкретной действительностью, общество проявляет себя с разных сторон и выглядит как сложно организованная система. В-третьих, в рассмотренных ранее подходах и концепциях анализировались связи состояния здоровья с различными факторами, среди которых стали преобладать поведенческие. Исследованы также факторы информированности, двигательной активности. В поле рассмотрения попали также здоровьесбережение, персональная ответственность за здоровье, способы выхода из стрессовых состояний. B-четвертых, особенную актуальность факторы приобретают в условиях Арктической зоны, с присущими особенностями климатогеографического положения и экстремальностью жизнеобеспечения. В-пятых, теоретическая модель является не только способом познания, но и управляющим инструментом исследования.

Ключевые слова: Арктическая зона Российской Федерации, Арктический регион, здоровье, здоровьесбережение, глобализация, модель. 
Ускорение социальных процессов в современном российском обществе, связанных с определенными процессами трансформации социально-политической системы на рубеже XXI в. проявились не только в усложнении и ускорении процессов, происходящих в социуме, но и в нарастании социальной напряженности. В последние десятилетия усугубляются глобальные проблемы человечества, появляются новые, отрицательные последствия которых имеют влияние и на состояние здоровья человека. Наблюдаются тенденции взаимозависимости также с экологической обстановкой техногенными процессами, а также с особенностями социально-политического развития страны. Претерпевает изменения также и образ жизни людей. Привычные формы активности вытесняются новыми возможностями для реализации личностного потенциала в новой технической и информационной реальности. Здоровье рассматривается прежде всего, как человеческий и социальный капитал.

Неблагоприятные климатические условия Арктической зоны Российской Федерации, ее уникальные климатогеографические, геофизические особенности, социальноэкономическое и научно-техническое развитие способствуют возрастанию значения здоровья населения при проживании в дискомфортных и зачастую экстремальных условиях.

Учитывая новейшие вызовы современности, вопросы здоровья и здоровьесбережения приобретают особую актуальность. Согласно Стратегии научно-технологического развития Российской Федерации, утвержденной Указом президента РФ № 642 от 01.12.2016, наиболее значимыми с точки зрения научно-технологического развития Российской Федерации большими вызовами являются переход, в том числе, и к технологиям здоровьесбережения, а также возможность эффективного ответа российского общества на большие вызовы с учетом взаимодействия человека и природы, человека и технологий, социальных институтов на современном этапе глобального развития, в том числе применяя методы гуманитарных и социальных наук [1].

Существующие концепции анализа ценности здоровья населения Арктическойзоны Российской Федерации оказались недостаточно полными с точки зрения учета новых тенденций развития социума в процессе глобализации и роботизирования социального пространства.

В социологических исследованиях последних десятилетий все чаще стали применяться разнообразные методы, одним из которых является моделирование. Под моделированием в социологическом анализе понимается метод исследования социальных явлений и процессов на определенных моделях, с опосредствованным рассмотрением социальных объектов, в результате которого происходит воспроизведение свойств во вспомогательной модели, позволяющей получать новое знание о предмете исследования или уточнения его характеристик.

Концептуальная модель, включающая понятийный аппарат, теоретикометодологические и аналитические подходы, особенности авторской позиции, а также описывающая методы и подходы социологического анализа ценности здоровья населения Арктической зоны Российской Федерации, опирается на теоретическую модель как возможную форму, обеспечивающую как логическую организацию, определенные значения, так и теоретически прогнозируемые связи между определенными нами понятиями. Более того, данная концепция предполагает определение понятия ценности здоровья населения, что является базовой компонентой в процессе конструирования модели. Также предполагается включение базисных понятий, таких как «Арктическая зона Российской Федерации», «здоровье» и др.

Из всей совокупности факторов, обуславливающих выделение компонентов теоретической составляющей модели, определенной целью и задачами исследования, мы выделяем три: 
1. Здоровье. Здоровье по своей социально-ценностной сущности - универсальное благо, имеющее смысложизненное значение для человека, обеспечивающее жизнь как наивысшую ценность [2]. Ценностное представление здоровья являет отношение социума к состоянию, определяющему и обуславливающему ценностные предпочтения.

Проблемы здоровья, здоровьесбережения всегда интересовали исследователей и занимали важное место в научной литературе. Еще со времен жреческой медицины здоровье человека рассматривалось как смысложизненная ценность человека. Такой подход представляли знаменитые ученые, философы того времени: Гиппократ, ИбнСина, Гален, Мартини, Селье и др.

Вопросы о долголетии и здоровье человека изучались еще в Древнем Китае и Индии в VI в. до н.э. историческим Буддой Шакьямуни, а также представителями школы Тяньтан в китайской провинции Аньхой. Им была присуща позиция рассмотрения человека и его здоровья как системы взаимосвязанных и взаимообусловленных компонентов существования всего материального бытия в целом. Впоследствии данные учения продолжали великие мастера Китая: Наньюэ, Лу Цзыцзянь и Мяолэ [3].

Проблемы здоровья с точки зрения социально-психологической и философской самоорганизации индивида анализировали В.М. Димов, В.Д. Жирнов, Р.С. Карпинская, Г.С. Корытова, И.К. Лисеев, В.М. Розин, Б.Г. Юдин и др. Взаимосвязи заболеваемости и образа жизни человека, факторов риска исследованы в работах А.М. Изуткиной, Ю.П. Лисицыной, И.В. Журавлевой, В.П. Петленко и др.

Существуют также исследования, в которых рассматриваются вопросы мировоззренческих оснований здоровья. Можно отметить труды А.А. Алексеева, А.В. Варфоломеева, Э.С. Демиденко, В.А. Иванченко, Т.Н. Светличной, Т.Я. Свищевой, М.И. Фомина, Л.В. Шаплыгина. Место здоровья в различных типах культур анализируют И.А. Бескова, Ю.П. Михаленко, С.А. Нижников.

Исследования ценностно-мотивационного компонента и ценности здоровья рассматривают А.И. Антонов, М.С. Бедный, В.А. Зотин, Ю.П. Лисицын, О.А. Харькова, В.А. Ядов и др.

Взаимосвязь социальных факторов и заболеваемости изучают Ю.А. Александровский, Т.А. Богорубова В.С. Гапилина, Ю.В. Гришко, Е.А. Маврина, Э.А. Мордовский, А.Л. Санников, А.Г. Соловьев и др.

Многие проблемы, связанные с анализом ценности здоровья населения Арктического региона Российской Федерации, остаются недостаточно изученными. Нет единства в толковании здоровья, его ценности. Зачастую определения приняты без учета результатов исследований естественных наук.

Так, Всемирная организация здравоохранения (ВО3), занимающаяся вопросами здоровья и здравоохранения во всем мире, декларирует определение здоровья как состояние полного физического, ментального и социального благополучия человека, а не только отсутствием болезней и физических дефектов [4]. Данная дефиниция закреплена в Уставе ВОЗ, подписанном 22 июля 1946 г. представителями 61 страны. С 1948 г. это определение не менялось [5].

2. Ценность здоровья. В современном обществе существует довольно много точек зрения социологической интерпретации понятия «ценность», а также свойственных ей характеристик. Поэтому необходимо проанализировать различные научные подходы к исследованию ценностей, а также последить взаимосвязь с социальным субъектом и объектом.

Впервые понятие «ценность» в научный оборот ввел Иммануил Кант, позиция которого отличалась автономностью свободной воли человека, независимостью ценно- 
стей от внешних обстоятельств, высшего источника. В отличие от большинства предшественников, допускающих религиозную составляющую в происхождении ценностей, И. Кант предположил, что мораль и долг существуют в разуме и не имеют божественной функции. Более того, Кант считает, что из морали возникает цель, имеющая «абсолютную ценность» - личность каждого человека. И. Кант утверждает, разумное существо «существует как цель сама по себе, а не только как средство», в отличие от предметов, независящих от нашей воли и которые «имеют, тем не менее, если они не наделены разумом, только относительную ценность как средства» [6].

Проблему ценностей в социологии рассматривал также Макс Вебер. Он представлял ценности с позиций неокантианства, исходя из предпосылок, что осмысленным каждое человеческое дело может считаться только в соотнесении с ценностями. Согласно концепции ценностных предпочтений определяются нормы поведения индивидов и их цели. Ценности отражают установки конкретного времени и приобретают относительные черты. М. Вебер подразумевал под ценностью установки исторической эпохи и разделял превращение индивидуального впечатления под воздействием исторической системы ценностей [7]. Значимым является понимание М. Вебером влияния формирования ценностей в зависимости от проявлений конкретного исторического периода, переживаемого индивидом и обществом в целом [8].

Эмиль Дюркгейм в своих работах описывал взаимовлияние норм общества, а также убеждений и ценностей индивидов. Коллективное сознание формирует общество и поддерживает его. В связи с этим коллективное сознание обладает ключевым, жизнеобеспечивающим значением для общества[9]. Особенно важно отметить актуальность взглядов Э. Дюркгейма в приложении к современному обществу, когда новые ценностные ориентиры навязываются человеку, создавая изменения в пространстве социума [10].

В отечественной литературе одними из первых исследователей, уделившими внимание проблемами ценностей, были В.А. Василенко и И.С. Нарский. Позднее изучением данных проблем занимались А.Г. Здравомыслов, О.Г. Добницын, Н.И. Лапин, В.П. Тугаринов, В.А. Ядов и др. Различные методики исследования ценностей предложили М. Рокич, Ш. Шварц, В.А. Ядов.

В разные годы проблемы здоровья как социальной ценности затрагивались при рассмотрении вопросов ценностных ориентаций личности, роли личности в истории, взаимовлияния техногенного аспекта. Этими вопросами занимались В.С. Барулин, Е.С. Демиденко, В.М. Димов, В.Д. Жирнов, А.Я. Иванюшкин, И.А. Крылова, И.С. Лаионова, В.Н. Паутов, И.В. Силуянова, В.Г. Федотова, Л.В. Фесенкова, А.Т. Шаталов.

Вопросы взаимосвязи заболеваемости и образа жизни населения, изучения факторов риска отражены в работах А.М.Изуткина, Ю.П. Лисицына, И.В. Журавлевой, В.П. Петленко, P.N. Hopkins, R.R. Williams и др.

Исследования ценностно-мотивационной структуры личности и связанных с ней ценностей здоровья отражено в работах А.И. Антонова, М.С. Бедного, В.А. Зотина, Ю.П. Лисицына, В.А. Ядова.

Значение социокультурных факторов в вопросах заболеваемости и смертности человека обсуждалось в трудах социолога и психиатра Джорджа Райла, благодаря которому появилось новое направление - социальная медицина [11].

Модель, предложенная биохимиком и социологом Лоуренсом Джозефом Хендерсоном, позволила показать роль особого характера живых систем. В своей книге «Социальная система»он предложил структурно-функциональную теорию соотношения 
физико-химических систем с социальными [12]. Обоснование важности изучения социального компонента в развитии общества представлено в работах Толкотта Парсонса. Эти основополагающие теоретические концепции явились предпосылками к появлению во второй половине XX в. социологии медицины [13].

3. Арктический регион. Для теоретической модели социологического анализа здоровья важно охарактеризовать понятие арктического региона. Существует достаточно большое количество определений данного понятия, разнородных по своей сути. Единого мнения по такому вопросу не удалось достичь. Даже при рассмотрении региональных вопросов дефиниция рассматривается под разными углами. Н.Н. Некрасов дает определение региону как «крупная территория страны с более или менее однородными природными условиями и характерной направленностью развития производительных сил на основе сочетания комплекса природных ресурсов с соответствующей сложившейся и перспективной материально-технической базой, производственной и социальной инфраструктурой. Основной критерий выделения региона - общность народнохозяйственных задач - основан на совокупности используемых или намечаемых к эксплуатации природных богатств, исторически сложившейся структуре хозяйственной деятельности» [14].Более общее представление изложил академик РАН А.Г. Гранберг: «Регион - это определенная территория, отличающаяся от других территорий по ряду признаков и обладающая некоторой целостностью, взаимосвязанностью составляющих ее элементов» [15].

Особенный физико-географический характер Арктической зоны Российской Федерации выделяет ее как природный регион, а также как специфическую, наиболее дискомфортную часть страны с экстремальными природными условиями. Составляющие территории Арктической зоны России имеют общие черты в своем хозяйственном комплексе: открытый выход к Мировому океану, большие запасы полезных ископаемых и биологических ресурсов, наличие морской инфраструктуры, высокие производственные издержки, связанные с тяжелыми климатогеографическими условиями ведения хозяйственной деятельности.

В соответствии с Указом Президента РФ от 02.05.2014 №2 96 «О сухопутных территориях Арктической зоны Российской Федерации» (в редакции указов Президента Российской Федерации от 27.06.2017 № 287, от 13.05.2019 № 220, от 05.03.2020 № 1 64) определены территории, относящиеся к Арктической зоне, в которую вошли территории Мурманской области, Ненецкого автономного округа, Чукотского автономного округа, Ямало-Ненецкого автономного округа, ряд муниципальных образований Архангельской области, земли и острова, расположенные в Северном Ледовитом океане, указанные в Постановлении Президиума Центрального Исполнительного Комитета СССР от 15 апреля 1926 г. «Об объявлении территорией Союза ССР земель и островов, расположенных в Северном Ледовитом океане» и других актах СССР [16].

Российская Федерация ратифицировала Конвенцию Организации Объединенных Наций по морскому праву Федеральным законом РФ от 26 февраля 1997 года № 30-ФЗ. В Конвенции предусмотрена возможность устанавливать ширину территориального моря государства до предела, не превышающего двенадцати морских миль, отмеряемых от исходных линий, определенных в соответствии с настоящей Конвенцией, а также 200 морских миль исключительной экономической зоны. В исключительной экономической зоне все государства, как прибрежные, так и не имеющие выхода к морю, пользуются свободами судоходства и полетов, прокладки подводных кабелей и трубопроводов и другими правомерными с точки зрения международного права видами использования моря [17]. 
Исследованиями проблематики арктической зоны Российской Федерации в разные годы занимались Г.А. Агранат, С.В. Баранов, Н.Ю. Гаврилов, Д.А. Гайнанов, К.С. Зайков, В.П. Карпов, Е.В. Кудряшова, Ю.Ф. Лукин, В.К. Мокшин, А.А. Сабуров, А.Н. Соловьёва, Ф.Х. Соколова, А.И. Татаркина.

Роль природно-климатических и экологических факторов арктической зоны в возникновении заболеваний, изменении состояния здоровья исследовали такие российские авторы, как А.П. Авцын, Р.М. Баевский, А.Б. Гудков, Г.Н. Дегтева, А.А. Ковшов, А.В. Кудрявцев, О.Н. Попова, Т.Н. Унгуряну, К.К. Холматова, В.П. Чащин и др.

Основные факторы, имеющие влияние на социально-экономическое развитие Арктической зоны Российской Федерации, являются: экстремальные природноклиматические условия, низкие температуры воздуха, сильные ветры, дискомфортные условия проживания населения; удаленность, высокая ресурсоемкость, низкая плотность населения; очаговый характер промышленно-хозяйственного освоения территорий, зависимость хозяйственной деятельности и жизнеобеспечения населения от поставок товаровиз других регионов России[18].

Согласно Стратегии развития Арктической зоны Российской Федерации и обеспечения национальной безопасности на период до 2020 г., утвержденной Президентом Российской Федерации 20.02.2013, Основам государственной политики Российской Федерации в Арктике на период до 2020 года и дальнейшую перспективу, утвержденным Президентом Российской Федерации 18.09.2008, определяются основные механизмы, способы и средства достижения устойчивого развития Арктической зоны, среди которых определено, в том числе, улучшение качества жизни населения, проживающего в Арктической зоне России, повышение уровня их социального и культурного обслуживания, а также развитие видов медицинской помощи, направленных на сохранение и укрепление здоровья населения, устранение вредного влияния факторов среды обитания, предупреждение возникновения и распространения заболеваний, раннее выявление их причин и условий развития, формирование и реализацию программ здорового образа жизни [19].

Резюмируя представленные компоненты, можем сделать важные выводы. Вопервых, создание теоретической модели и ее использование в социологическом анализе ценности здоровья населения Арктического региона Российской Федерации и представление исследуемого объекта с разных сторон позволяет достичь наибольшей содержательности и полноты понятий, относящихся к данной области знаний.

Во-вторых, содержание теоретической модели, предлагаемой нами, представляет собой определенную целостность, которая в неразрывном единстве включает изучение конкретных аспектов жизни общества, взаимосвязи в нем, а также возможности и способы его использования в исследовательской деятельности. Благодаря моделированию, при сопоставлении характеристик с конкретной действительностью, общество проявляет себя с разных сторон и выглядит как сложно организованная система.

В-третьих, в рассмотренных ранее подходах и концепциях анализировались связи состояния здоровья с различными факторами, среди которых стали преобладать поведенческие. Исследованы также факторы информированности, двигательной активности. В поле рассмотрения попали также здоровьесбережение, персональная ответственность за здоровье, способы выхода из стрессовых состояний.

В-четвертых, особенную актуальность факторы приобретают в условиях Арктической зоны, с присущими особенностями климатогеографического положения и экстремальностью жизнеобеспечения.

В-пятых, теоретическая модель является не только способом познания, но и управляющим инструментом исследования. 


\section{СПИСОК ЛИТЕРАТУРЫ}

1. Стратегии научно-технологического развития Российской Федерации. URL: http://static.kremlin.ru/ media/events/files/ru/uZiATIOJiq5tZsJgqcZLY9YyL8PWTXQb.pdf (дата обращения 01.07.2020).

2. Козел В.И. Формирование готовности личности к конструктивному самоутверждению. - Барановичи: РИО БарГУ, 2009. - 239 с.

3. Махаматов Т.Т. Здоровье и долголетие в традиции лотосовой сутры в Китае // Человек. - 2011. № 3. - C.78-83.

4. Basic documents // World Health Organization.URL: https://apps.who.int/gb/bd/pdf_files/BD_49th-en.pdf (дата обращения 01.07.2020).

5. Устав Всемирной организации здравоохранения. - Женева: ВОЗ, 2020. - 629 с.

6. Кант И. Сочинения в шести томах. Т. 4. Ч. 1. - М.: Мысль, 1965. - 544 с.

7. Вебер М. Наука как призвание и профессия // Избранные произведения. - М.: Прогресс, 1990. C.707-735.

8. Шацкий Е. История социологической мысли. Т. 2. - М.: Новое лит. обозрение, 2018. - 720 с.

9. Дюркгейм Э. Социология. Ее предмет, метод, предназначение. - М.: Канон, 1995. - 352 с.

10. Гофман А.Б. Э. Дюркгейм о ценностях и идеалах // Социологические исследования. - 1991. - № 2. C. 104-106.

11. Ryle J.A. Social medicine: its meaning and its scope // British medical journal. - 1943. - V. 2. - no. 4324. C. 633.

12. Henderson L.J. L.J. Henderson on the Social System. - Chicago: University of Chicago Press, 1970. $272 \mathrm{p}$.

13. Allan K. Explorations in classical sociological theory: seeing the social world. - Thousand Oaks: Pine Forge Press, 2005. -395 p.

14. Некрасов Н.Н. Региональная экономика. Теория, проблемы, методы. - М.: Экономика, 1978. - 343 с.

15. Гранберг А.Г. Основы региональной экономики. - М.: ГУ ВШЭ, 2001. -495 с.

16. О сухопутных территориях Арктической зоны Российской Федерации: указ Президента РФ от 02.05.2014 № 296. URL: http://kremlin.ru/acts/bank/38377 (дата обращения 01.07.2020).

17. Конвенция Организации Объединенных Наций по морскому праву. URL: http://docs.cntd.ru/document/1900747 (дата обращения 01.07.2020).

18. Bulanova Y.V. The demographic potential of Russia's arctic and subarctic regions by the example of Arkhangelsk region // IOP conference series: earth and environmental science. - 2019. DOI:10.1088/17551315/263/1/012044. URL: https://www.elibrary.ru/item.asp?id=41665274 (дата обращения 01.07.2020).

19. О Стратегии развития Арктической зоны Российской Федерации и обеспечения национальной безопасности на период до 2020 года. URL: http://government.ru/info/18360 (дата обращения 01.07.2020).

Поступила 12.07.2020 2. 
UDC 316.334.6:364.2:61(985)

\title{
THEORETICAL MODEL OF SOCIOLOGICAL ANALYSIS OF THE VALUES OF POPULATION HEALTH IN THE ARCTIC REGION OF THE RUSSIAN FEDERATION
}

\author{
Yulia V. Bulanova, \\ ybus@mail.ru \\ North State Medical University, \\ 51, Troitsky avenue, Arkhangelsk, 163000, Russia
}

Yulia V. Bulanova, junior researcher, North State Medical University.

The article presents a theoretical model of a sociological analysis of the value of health as a multicomponent system, a description of the components of the model and their characteristics. The factors of awareness, behavioral activity, health conservation, personal responsibility for health are investigated. Particular relevance was emphasized in the conditions of the Arctic zone, with the inherent features of the climatic and geographical position and the extremeness of life support. The relevance of research. The issues of studying the value of public health have become relevant in the context of globalization of the twenty-first century. There is a need to solve the problems of maintaining human health. This problem is especially acute in the conditions of the Arctic zone of the Russian Federation. Natural and anthropogenic factors place increased demands on the functional systems of the human body, complicate the work, life and leisure of the population, being risk factors for health problems. The health problems were especially relevant during the pandemic of the new coronavirus COVID-19. This is one of the worst global health crises in 50 years. The issues of ensuring sanitary and epidemiological well-being, health conservation, and increasing the value of health have come to the fore. The aim of the work is to consider the health value of the population of the Arctic region of the Russian Federation through the prism of theoretical foundations and institutional approaches. Methods: the axiological approach, which assumes a value measurement of the studied socio-cultural phenomena and the socio-constructivist approach, which considers the value of the health of the population of the Arctic region as a necessary social paradigm. Conclusions. First, the creation of a theoretical model and its use in a sociological analysis of the health value of the population of the Arctic region of the Russian Federation and the presentation of the studied object from different angles allows us to achieve the most content and completeness of concepts related to this field of knowledge. Secondly, the content of the theoretical model proposed represents a certain integrity, which in indissoluble unity includes the study of specific aspects of society, the relationship in it, as well as the possibilities and methods of its use in research. Thanks to modeling, when comparing the characteristics with a specific reality, society manifests itself from different angles, and looks like a complex organized system. Thirdly, in the approaches and concepts considered earlier, the relationships of the state of health with various factors were analyzed, among which behavioral one began to prevail. The factors of awareness, motor activity were also investigated. Health protection, personal responsibility for health, and ways out of stressful conditions also fell into the field of consideration. Fourthly, factors acquire special relevance in the Arctic zone, with the inherent features of the climatic and geographical position and the extremeness of life support. Fifth, the theoretical model is not only a way of cognition, but also a governing tool of research.

Key words: Arctic zone of the Russian Federation, Arctic region, health, health conservation, globalization, model.

\section{REFERENCES}

1. Strategii nauchno-tekhnologicheskogo razvitiya Rossiyskoy Federatsii [Strategies for the scientific and technological development of the Russian Federation]. Available at: http://static.kremlin.ru/media/ events/files/ru/uZiATIOJiq5tZsJgqcZLY9YyL8PWTXQb.pdf (accessed 7 January 2020). 
2. Kozel V.I. Formirovanie gotovnosti lichnosti k konstruktivnomu samoutverzhdeniyu [Formation of the individual's readiness for constructive self-affirmation]. Baranovichi, RIO BarSU Publ., 2009. 239 p.

3. Makhamatov T.T. Zdorove i dolgoletie $\mathrm{v}$ traditsii lotosovoy sutry v Kitae [Health and longevity in the tradition of the lotus sutra in China]. Chelovek, 2011, no. 3, pp. 78-83.

4. Basic documents. World Health Organization. Available at: https://apps.who.int/gb/bd/pdf_files/BD_49then.pdf (accessed 7 January 2020).

5. Ustav Vsemirnoy organizatsii zdravookhraneniya [Charter of the World Health Organization]. Geneva, WHO Publ., 2020. 629 p.

6. Kant I. Sochineniya v shesti tomakh. T. 4. Ch. 1 [Works in six volumes. Vol. 4. P. 1]. Moscow, Mysl Publ., 1965. 544 p.

7. Weber M. Nauka kak prizvanie i professiya [Science as a vocation and profession]. Izbrannye proizvedeniya [Selected works]. Moscow, Progress Publ., 1990. pp. 707-735.

8. Shatskiy E. Istoriya sotsiologicheskoy mysli. T. 2 [History of sociological thought. Vol. 2]. Moscow, NLO Publ., 2018. 720 p.

9. Durkheim E. Sotsiologiya. Ee predmet, metod, prednaznachenie [Sociology. Its subject, method, purpose]. Moscow, Canon Publ., 1995. 352 p.

10. Hoffman A.B. Dyurkgeym o tsennostyakh i idealakh [E. Durkheim on values and ideals]. Sotsiologicheskie issledovaniya, 1991, no. 2, pp. 104-106.

11. Ryle J.A. Social medicine: its meaning and its scope. British medical journal, 1943, vol. 2, no. 4324, p. 633.

12. Henderson L.J. L.J. Henderson on the Social System. Chicago, University of Chicago Press, 1970. 272 p.

13. Allan K. Explorations in classical sociological theory: seeing the social world. Thousand Oaks, Pine Forge Press, 2005. 395 p.

14. Nekrasov N.N. Regionalnaya ekonomika. Teoriya, problemy, metody [Regional economy. Theory, problems, methods]. Moscow, Economics Publ., 1978. 343 p.

15. Granberg A.G. Osnovy regionalnoy ekonomiki [Fundamentals of regional economics]. Moscow, GU HSE Publ., 2001. 495 p.

16. O sukhoputnykh territoriyakh Arkticheskoy zony Rossiyskoy Federatsii [On the land territories of the Arctic zone of the Russian Federation]. Ukaz Prezidenta RF ot 02.05.2014 № 296 [Decree of the President of the Russian Federation of 05.02.2014 no. 296]. Available at: http://kremlin.ru/acts/bank/38377 (accessed 7 January 2020).

17. Konventsiya Organizatsii Obedinennykh Natsiy po morskomu pravu [United Nations Convention on the Law of the Sea]. Available at: http://docs.cntd.ru/document/1900747 (accessed 7 January 2020).

18. Bulanova Y.V. The demographic potential of Russia's arctic and subarctic regions by the example of Arkhangelsk region. IOP conference series: earth and environmental science. 2019. DOI:10.1088/17551315/263/1/012044. Available at: https://www.elibrary.ru/item.asp?id=41665274 (accessed 1 July 2020).

19. O Strategii razvitiya Arkticheskoy zony Rossiyskoy Federatsii i obespecheniya natsionalnoy bezopasnosti na period do 2020 goda [About the Strategy for the development of the Arctic zone of the Russian Federation and ensuring national security for the period up to 2020]. Available at: http: //government.ru/info/18360 (accessed 7 January 2020).

Received: 12 July 2020. 